\title{
Role of Insulin-like Growth Factor-1 in the Central Regulation of Feeding Behavior in Chicks
}

\author{
Shoichi Fujita, Kazuhisa Honda, Mika Yamaguchi, Satoshi Fukuzo, \\ Takaoki Saneyasu and Hiroshi Kamisoyama
}

Department of Bioresource Science, Graduate School of Agricultural Science, Kobe University, Kobe 657-8501, Japan

\begin{abstract}
Insulin-like growth factor-1 (IGF-1) is a key regulator of muscle development and metabolism in chickens. Recently, we have demonstrated that intracerebroventricular administration of IGF-1 significantly decreased food intake in broiler chicks. However, the molecular mechanisms underlying the IGF-1-induced anorexia and the anorexigenic effect of IGF-1 in different strains of commercial chicks have not been investigated. Neuropeptide Y (NPY, a hypothalamic orexigenic neuropeptide), agouti-related protein (AgRP, a hypothalamic orexigenic neuropeptide), and proopiomelanocortin (POMC, the precursor of hypothalamic anorexigenic neuropeptides) play important roles in the regulation of food intake in both mammals and chickens. Evidence shows that several cell signaling pathways in the hypothalamus are involved in regulating the feeding behavior of mammals. In the present study, we first investigated the effects of IGF-1 on the expression of appetite-regulating neuropeptides and phosphorylation of signaling molecules in the hypothalamus of broiler chicks. Intracerebroventricular administration of IGF-1 significantly increased the mRNA levels of POMC, whereas the mRNA levels of NPY and AgRP were not significantly altered. IGF-1 also significantly induced the phosphorylation of v-Akt murine thymoma viral oncogene homolog 1 (AKT) in the hypothalamus of chicks, but did not influence the phosphorylation of forkhead box O1, S6 protein, AMP-activated protein kinase, and extracellular signal-regulated kinase $1 / 2$. We also compared the effect of IGF-1 on food intake in broiler chicks (a hyperphagic strain of chickens) and layer chicks. Results demonstrated that the threshold of IGF-1-induced anorexia in broiler chicks was higher than that in layer chicks. Our observations suggest that hypothalamic POMC and AKT may be involved in the IGF-1-induced anorexigenic pathway and that high threshold of IGF-1-induced anorexia in broiler chicks might be one of the causes of hyperphagia in broiler chicks. Overall, it appears that IGF-1 plays important roles in the central regulation of feeding behavior in chicks.
\end{abstract}

Key words: appetite, brain, chick, feed intake, peptide

J. Poult. Sci., 56: 270-276, 2019

\section{Introduction}

Insulin-like growth factor-1 (IGF-1) is a key regulator of muscle development and metabolism in chickens. For example, IGF-1 increased cell protein content in chicken myotube (Nakashima et al., 2017) and promoted chicken myoblast proliferation (Yu et al., 2015). Tomas et al. (1998) reported enhancement of growth and feed efficiency of broiler chickens receiving exogenous IGF-1. Blood IGF-1 level is

Received: November 13, 2018, Accepted: January 17, 2019

Released Online Advance Publication: February 25, 2019

Correspondence: Kazuhisa Honda, Ph. D., Department of Bioresource Science, Graduate School of Agricultural Science, Kobe University, Kobe 657-8501, Japan. (E-mail: honda@tiger.kobe-u.ac.jp)

The Journal of Poultry Science is an Open Access journal distributed under the Creative Commons Attribution-NonCommercial-ShareAlike 4.0 International License. To view the details of this license, please visit (https:// creativecommons.org/licenses/by-nc-sa/4.0/). elevated by refeeding (Kita et al., 1996, 1998) but decreased by restriction feeding (Leili et al., 1997) in layer chickens. Evidence shows that the plasma IGF-I profile coincided with the expression of hepatic IGF-I mRNA in broiler (Burnside and Cogburn, 1992) and layer (Kita et al., 1998) chickens. Recently, we observed that refeeding increased the mRNA levels of IGF-1 in the liver of broiler chicks (Fujita et al., 2017). Thus, IGF-1 plays important roles as an anabolic hormone in chickens in response to feeding.

Recently, we observed that central administration of IGF-1 significantly suppressed food intake in broiler chicks (Fujita et al., 2017). However, the molecular mechanisms underlying the IGF-1-induced anorexia in chicks have not been investigated. Physiological and molecular mechanisms involved in the regulation of food intake in chickens have recently been investigated (Kuenzel, 1994, Richard and Proszkowiec-Weglarz, 2007; Honda et al., 2017). In mammals and birds, two neuronal populations within the hypo- 
thalamus, namely, the orexigenic neuropeptide Y(NPY)/agoutirelated protein (AgRP) neurons and the anorexigenic proopiomelanocortin (POMC) neurons, are believed to be critical conduits via which peripheral signals are integrated to alter the drive to eat (Bungo et al., 2011; Sam et al., 2012; Zeltser et al., 2012). Kim et al. (2006) reported that a nuclear transcription factor forkhead box O1 (FOXO1), which is directly phosphorylated by v-Akt murine thymoma viral oncogene homolog 1 (AKT), plays important roles in the transcriptional regulation of NPY, AgRP, and POMC in the mammalian hypothalamus. Blouet et al. (2008) proposed that mediobasal hypothalamic p70 S6 kinase 1 (S6K1), a major downstream effector of the mechanical target of rapamycin (mTOR), controls food intake by regulating the expression of AgRP and NPY. mTOR, S6K1, and S6 proteins act downstream of AKT in mammals and chickens (Tesseraud et al., 2007). We recently suggested that hypothalamic AKT signaling is involved in the regulation of food intake in chicks (Saneyasu et al., 2018). IGF-1 promotes myoblast proliferation and skeletal muscle growth of embryonic chickens via AKT signaling (Yu et al., 2015). All these observations prompted the hypothesis that IGF-1 suppresses food intake through the AKT signaling pathway in chicks.

Song et al. (2012) and Liu et al. (2014) proposed that hypothalamic AMP-activated protein kinase (AMPK) regulates the transcription of hypothalamic neuropeptides in chickens. Radhakrishnan et al. (2010) proposed that IGF can activate mitogen-activated protein kinase/extracellular signal-regulated kinase (ERK) under high glucose conditions in mammals. Birds maintain higher plasma glucose concentrations than other vertebrates of similar body mass (Braun and Sweazea, 2008). Therefore, it is possible that AMPK and ERK $1 / 2$ are involved in the anorexigenic action of IGF-1 in chicks.

Understanding the regulatory mechanism of feed intake in commercial chickens is important as metabolic diseases in broiler and layer chickens are serious problems in the poultry industry (Julian, 2005). Several peptides or hormones show different effect on food intake between broiler and layer chicks (Tachibana et al., 2001; 2003; 2006; Shiraishi et al., 2011; Honda et al., 2012). However, the anorexigenic effect of IGF-1 in layer chicks has not yet been investigated.

In this study, we attempted to elucidate the mechanism underlying the IGF-1-induced anorexia in broiler chicks. Toward this, we investigated the effects of central administration of IGF-1 on the mRNA levels of appetite-regulating neuropeptides and signaling pathways in the hypothalamus of broiler chicks. We also compared the effect of central administration of IGF-1 on food intake in broiler and layer chicks. Our observations indicate a role of IGF-1 in the central regulation of feeding behavior in chicks.

\section{Materials and Methods}

\section{Animals and Peptides}

This study was approved by the Institutional Animal Care and Use Committee and was performed according to the Kobe University Animal Experimentation Regulation (2707-01). One-day-old male chicks (Ross 308) were purchased from a local hatchery (Yamamoto Co. Ltd., Kyoto, Japan for Experiments 1 and 2 and Ishii Co. Ltd., Tokushima, Japan for Experiment 3). One-day-old male layer chicks (White leghorn) were purchased from a local hatchery (Japan Layer K. K., Gifu, Japan). They were given free access to water and a commercial chick starter diet (Nichiwa Sangyo Co., Ltd., Kobe, Japan). Human IGF-1 was purchased from Novus Biologicals, LLC (Co, USA).

Experiment 1. Effect of Central Administration of IGF-1 on the mRNA Levels of Hypothalamic Neuropeptides in Chicks

Twenty-four 8-day-old chicks were weighed and allocated to two groups based on body weight. IGF-1 was dissolved in $0.85 \%(\mathrm{w} / \mathrm{v})$ saline solution containing $0.1 \%(\mathrm{w} / \mathrm{v})$ Evans Blue. Either 0 (control) or $300 \mathrm{pmol}$ IGF-1 in a volume of $10 \mu \mathrm{L}$ was intracerebroventricularly administered according to the method of Davis et al. (1979). At $30 \mathrm{~min}$ after administration, the chicks were euthanized by decapitation. The success of the injection was verified by observing the presence of Evans Blue dye in the lateral ventricle. The diencephalon was collected and preserved in RNAlater ${ }^{\circledR}$ tissue storage reagent (Sigma-Aldrich Co., St. Louis, MO, USA). Total RNA extraction and cDNA synthesis were performed as described previously (Honda et al., 2015). cDNA of NPY (GenBank accession no. NM_205473), AgRP (GenBank accession no. AB029443), and POMC (GenBank accession no. NM_001031098) were amplified using the following primers: NPY sense, $5^{\prime}$-CTT GTC GCT GCT GAT CTG -3'; NPY antisense, 5' -GCC TCA GAG CCG AGT AGT-3' ; AgRP sense, 5' -GCA GGA AGG TGA TGG TAA C-3'; AgRP antisense, $5^{\prime}$-GTC ACA GCA GGG GAT CTG-3' ; POMC sense, 5' -AGA TGG AGA AGG GTT GGA A-3'; and POMC antisense, $5^{\prime}$-CGT TGG GGT ACA CCT TGA-3' . cDNA of ribosomal protein S17 as an internal standard was amplified using primers as described previously (Saneyasu $e t$ al., 2016). mRNA levels were quantified in duplicate using PikoReal ${ }^{\mathrm{TM}}$ kit (Thermo Fisher Scentific K.K. Tokyo, Japan) and SYBR ${ }^{\circledR}$ Premix Ex Taq ${ }^{\mathrm{TM}}$ II (Tli RNaseH Plus) (Takara Bio Inc., Shiga, Japan) according to the supplier's recommendations.

Experiment 2. Effect of Central Administration of IGF-1 on the Protein Levels of Hypothalamic Signaling Pathways in Chicks

Twenty-four 8-day-old chicks were weighed and allocated to two groups based on body weight, and either 0 (control) or 300 pmol IGF-1 was intracerebroventricularly administered as described above. At $30 \mathrm{~min}$ after administration, the chicks were euthanized by decapitation. The success of the injection was verified as described in Experiment 1. The hypothalamus was dissected, immediately frozen in liquid nitrogen, and stored at $-80^{\circ} \mathrm{C}$. Western blot analysis was performed as previously reported (Saneyasu et al., 2017). The frozen hypothalamus was ultrasonicated in a lysis buffer. Homogenates were centrifuged at $17,900 \times g$ for $15 \mathrm{~min}$ at $4^{\circ} \mathrm{C}$ and the supernatants were stored at $-80^{\circ} \mathrm{C}$. Protein concentrations were determined using Lowry's method. Lysates were subjected to sodium dodecyl sulfate-polyacrylamide gel 
electrophoresis (SDS-PAGE) and western blotting using the HorizeBlot (ATTO Co., Tokyo, Japan) according to the manufacturer's instructions. Bands were detected using ChemiLumi one Super (Nacalai Tesque, Inc., Kyoto, Japan), visualized using LumiCube (Liponics Inc., Tokyo, Japan), and quantified using the CS Analyzer software (ATTO Co., Tokyo, Japan). Anti-Akt (\#9272), anti-phospho-Akt (pAkt) (Thr308) (\#9275), anti-pAkt (Ser473) (\#9271), anti-S6 ribosomal protein (S6) (\#2217), anti-phospho-S6 ribosomal protein (pS6) (Ser240/244) (\#5364), anti-FOXO1 (\#9454), anti-phospho-FOXO1 (pFOXO1) (Ser256) (\#9461), anti- $\beta$ actin (\#4967), anti-AMPK (\#2532), anti-phospho-AMPK (pAMPK) (Thr172) (\#2531), anti-ERK1/2 (\#4695), antiphospho-ERK1/2 (\#9101) (Thr202/Tyr204) (\#4370), anti$\alpha / \beta$-tubulin (\#2148) and horseradish peroxidase (HRP) conjugated anti-rabbit IgG (\#7074) were purchased from Cell Signaling Technology (Beverly, MA, USA).

Experiment 3. Effects of Central Administration of IGF-1 on Food Intake in Broiler and Layer Chicks

Thirty-six 7-day-old broiler chicks or thirty-six 8-day-old layer chicks were fasted for $3 \mathrm{~h}$, weighed, and allocated to four groups based on body weight. Either 0,30 , or $300 \mathrm{pmol}$ IGF-1 was intracerebroventricularly administered as described above. Food intake was measured at 30, 60, and 120 min after administration. At the end of the experiment, the chicks were euthanized by decapitation. The success of the injection was verified as described in Experiment 1.

Data Analysis

Data from Experiments 1 and 2 were analyzed using Student's $t$-test. Data from the Experiment 3 were analyzed using the Tukey-Kramer test. All statistical analyses were performed using the commercial package (StatView version 5, SAS Institute, Cary, NC, USA, 1998).

\section{Results and Discussion}

In the present study, we first examined the effect of central administration of IGF-1 on the expression of appetite regulation-related genes in chick hypothalamus and observed that IGF-1 significantly increased the mRNA levels of POMC (Fig. 1). However, IGF-1 did not alter the mRNA levels of $N P Y$ and $A g R P$ (Fig. 1). In mammals, POMC expression is suppressed by unphosphorylated FOXO1, and AKT promotes cytoplasmic translocation of FOXO1 after phosphorylation (Sasaki and Kitamura, 2010). Therefore, we next assessed the effect of central administration of IGF-1 on the phosphorylation of AKT signaling molecules in chick hypothalamus. IGF-1 significantly increased AKT phosphorylation, whereas the phosphorylation of FOXO1 and S6 was not induced (Fig. 2). As mentioned in the Introduction, AMPK and ERK $1 / 2$ are possibly involved in the anorexigenic action of IGF-1 in chicks. Therefore, we further analyzed the phosphorylation of AMPK and ERK1/2 and observed that IGF-1 did not affect the phosphorylation of these proteins (Fig. 3). These observations suggest that hypothalamic POMC and AKT may be involved in the IGF-1-induced anorexigenic pathway.

We also compared the effect of IGF-1 on food intake
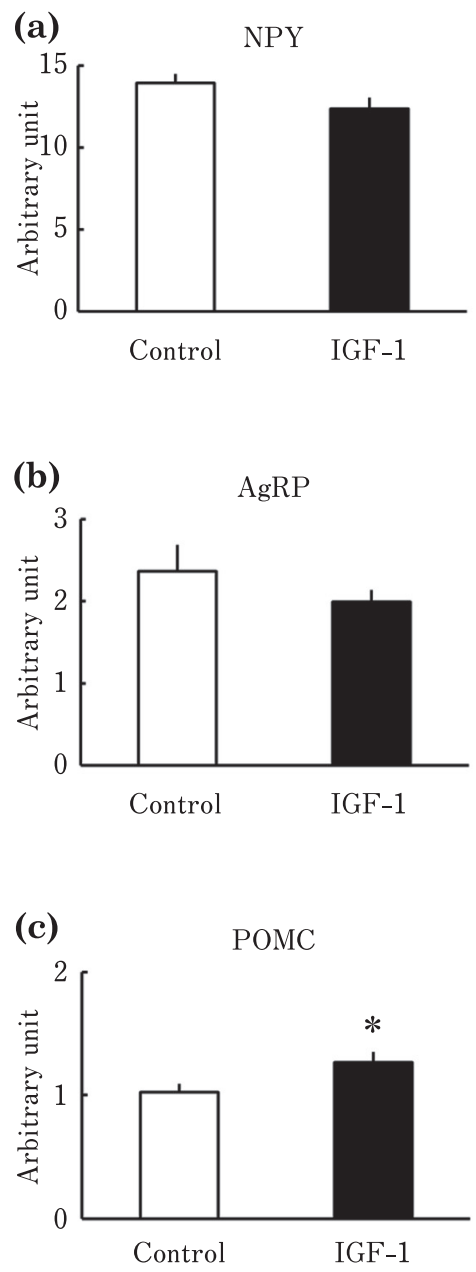

Fig. 1. Effects of central administration of insulin-like growth factor-1 (IGF-1) on the mRNA levels of appetite regulation-related genes $N P Y$ (a), $A g R P$ (b), and $P O M C$ (c) in chick hypothalamus. Data represent means \pm S.E.M $(n=11) . *$, Significant with respect to the control group ( $p$ $<0.05)$.

between broiler and layer chicks. Intracerebroventricular administration of IGF-1 significantly decreased food intake in both types of chicks. However, the threshold of IGF-1induced anorexia in broiler chicks $(300 \mathrm{pmol})$ was higher than that in layer chicks $(30 \mathrm{pmol})$ (Fig. 3). These results indicate low IGF-1 sensitivity of the hypothalamus of broiler chicks.

Jia et al. (2018) reported that broiler chicks showed higher plasma IGF-1 concentration than native chicken breeds. Fast-growing broilers had higher concentrations of IGF-1 in the serum than slow-growing broilers (Xiao et al., 2017). Thus, high concentration of plasma IGF-1 may possibly be one of the causes of fast growth of broiler chickens. In addition, the present study clearly demonstrates that the threshold of IGF-1-induced anorexia in broiler chicks was higher than that in layer chicks. Broiler chickens consume 

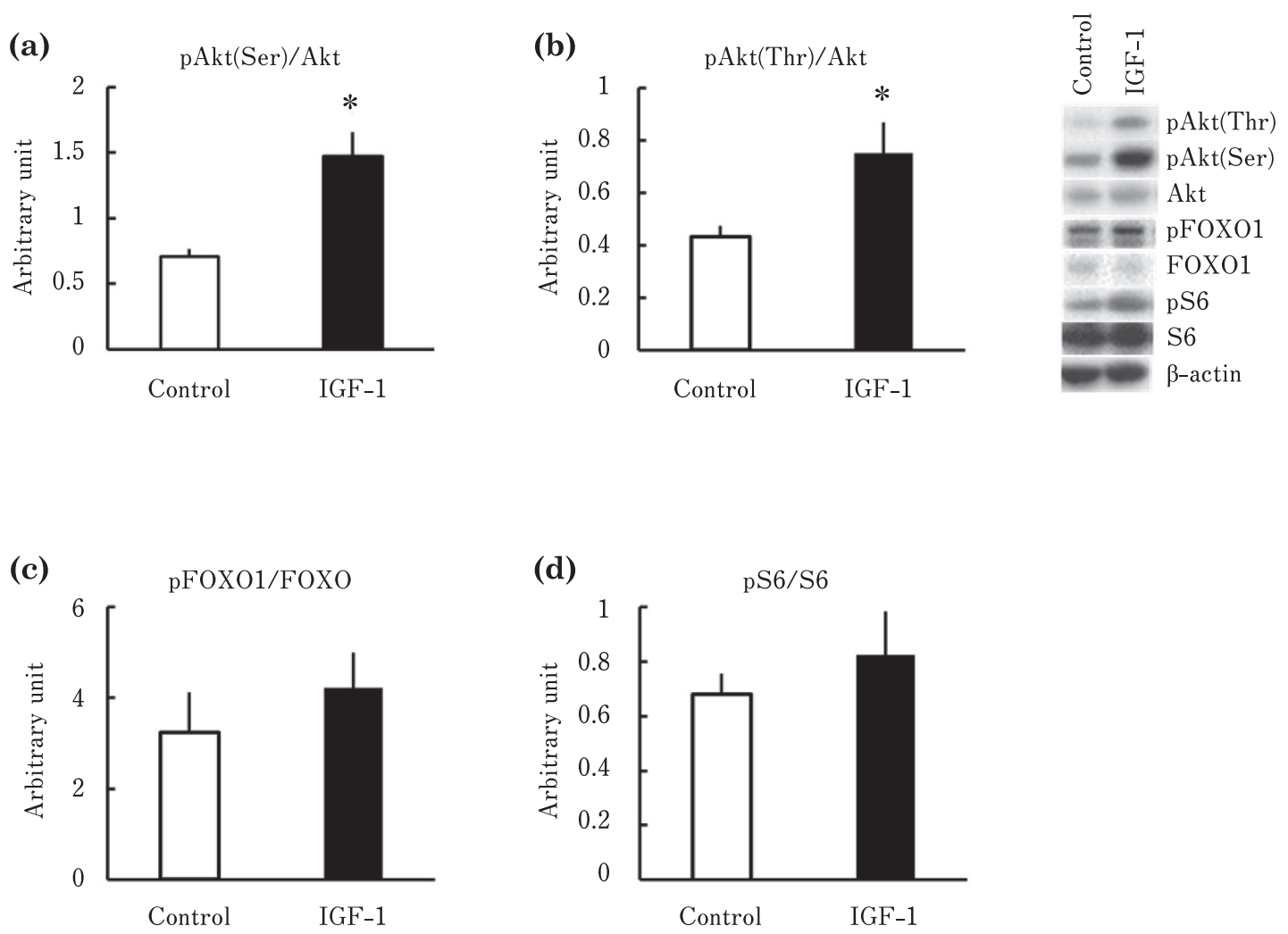

Fig. 2. Effects of central administration of insulin-like growth factor-1 (IGF-1) on the phosphorylation of AKT (Ser) (a), AKT (Thr) (b), FOXO1 (c), and S6 (d) in chick hypothalamus. Data represent means $\pm \operatorname{SEM}(n=8) . *$, Significant with respect to the control group $(p<0.05)$.

more food (Yuan et al., 2009; Saneyasu et al., 2011) and grow faster (Zhao et al., 2004; Wilson et al., 2018) than layer chickens. Therefore, it is possible that the high threshold of IGF-1-induced anorexia in broiler chicks is also one of the causes underlying their fast growth.

In the present study, layer chicks showed a lower threshold of central IGF-1-induced anorexia than the broiler chicks. Shiraishi et al. (2011) reported insulin resistance in broiler chicks; central administration of insulin suppressed food intake in layer chicks, but not in broiler chicks. Therefore, differences in the sensitivity of chicks to IGF-1 and insulin may be responsible for hyperphagia in broiler chicks. We have previously shown that intracerebroventricular administration of insulin induces phosphorylation of AKT and FOXO1 in the hypothalamus of layer chicks (Saneyasu et al., 2018). In the present study, IGF-1 significantly induced AKT phosphorylation in the hypothalamus of chicks but did not affect FOXO1 phosphorylation. In addition, we observed the same phenomenon in insulin-administrated broiler chicks (unpublished data). Therefore, differences in the response to the hypothalamic AKT/FOXO signaling between broiler and layer chicks may be responsible for differences in the effective doses of IGF-1 and other hormones, such as insulin.
Further studies are required to clarify the effect of IGF-1 on hypothalamic AKT/FOXO signaling in layer chicks.

AKT/FOXO signaling regulates food intake through the transcription of $N P Y, A g R P$, and $P O M C$; the unphosphorylated form of FOXO1 stimulated the transcription of $N P Y$ and $A g R P$ but suppressed that of $P O M C$ in the hypothalamus of mammals (Kim et al., 2006). In the present study, IGF-1 did not affect the phosphorylation of FOXO1, although it tended to reduce the levels of total FOXO1 $(p=0.077$, data not shown). Therefore, it is possible that IGF-1 decreases the level of unphosphorylated FOXO1, which in turn upregulates $P O M C$. However, why IGF-1 did not reduce the mRNA levels of $N P Y$ and $A g R P$ is not clear. In rats, adenovirusmediated constitutive activation of mediobasal S6K1 decreased the mRNA levels of $N P Y$ and $A g R P$ without affecting $P O M C$ mRNA levels (Blouet et al., 2008). Furthermore, IGF-1 did not induce the phosphorylation of the S6 protein, suggesting that S6K1 was not activated. Evidence shows that mTOR, an upstream activator of S6K1, can be regulated in an AKT-independent manner (Sasaki and Kitamura, 2010; Haissaguerre et al., 2014). Therefore, as the mTOR-S6K1 pathway is not activated by IGF-1, significant changes might not be detected in the mRNA levels of $N P Y$ and $A g R P$. 
(a)
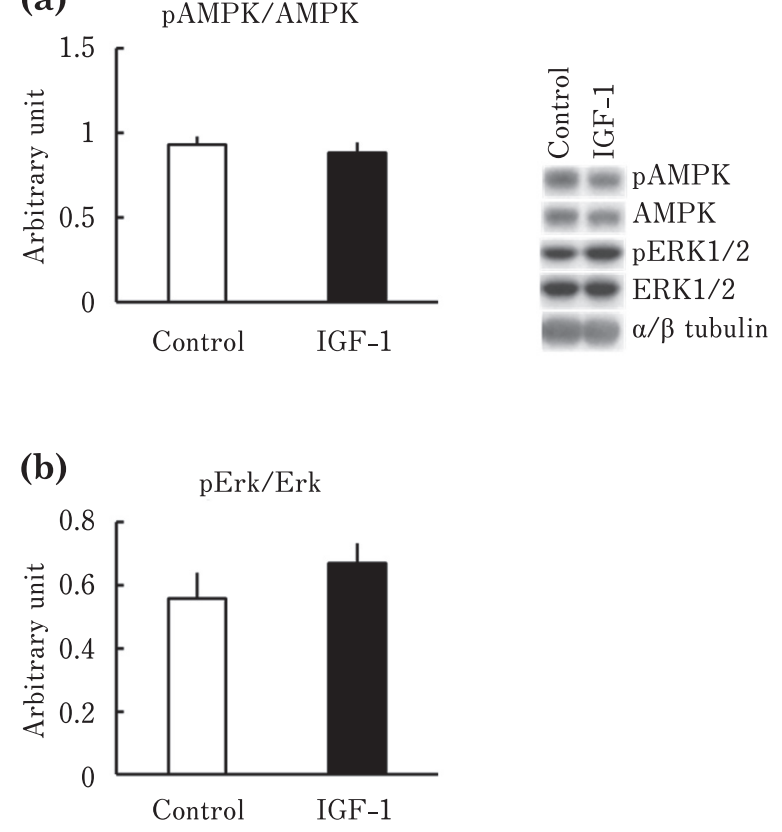

Fig. 3. Effects of central administration of insulin-like growth factor-1 (IGF-1) on the phosphorylation of AMPK (a) and ERK1/2 (b) in chick hypothalamus. Data represent means \pm SEM $(n=8)$.

Intracerebroventricular administration of IGF-1 did not influence food intake in normal rats but significantly decreased food intake in diabetic rats (Lu et al., 2001). Therefore, the anorexigenic effect of IGF-1 might be observed under hyperglycemic condition in rats. Birds maintain higher plasma glucose concentrations than other vertebrates of similar body mass (Braun and Sweazea, 2008). Therefore, central administration of IGF-1 showed anorexigenic effect in chicks as well as in diabetic rats. In chickens, blood glucose (Saneyasu et al., 2013) and IGF-1 (Kita et al., 1998) levels are elevated after food intake. Therefore, glucose and IGF-1 might coordinately regulate appetite as a nutritional and hormonal satiety signal in chickens.

In conclusion, we observed that intracerebroventricular administration of IGF-1 significantly increased POMC mRNA levels and induced AKT phosphorylation in broiler chicks. We also showed that the threshold of IGF-1-induced anorexia in broiler chicks was higher than that in layer chicks. Our observations suggest that IGF-1 may play important roles in the central regulation of feeding behavior and that the low IGF-1 sensitivity in the hypothalamus may be one of the causes of hyperphagia in broiler chicks.

\section{Conflict of Interest}

The authors declare no conflict of interest.

\section{References}

Blouet C, Ono H and Schwartz GJ. Mediobasal hypothalamic p70 S6 kinase 1 modulates the control of energy homeostasis. Cell
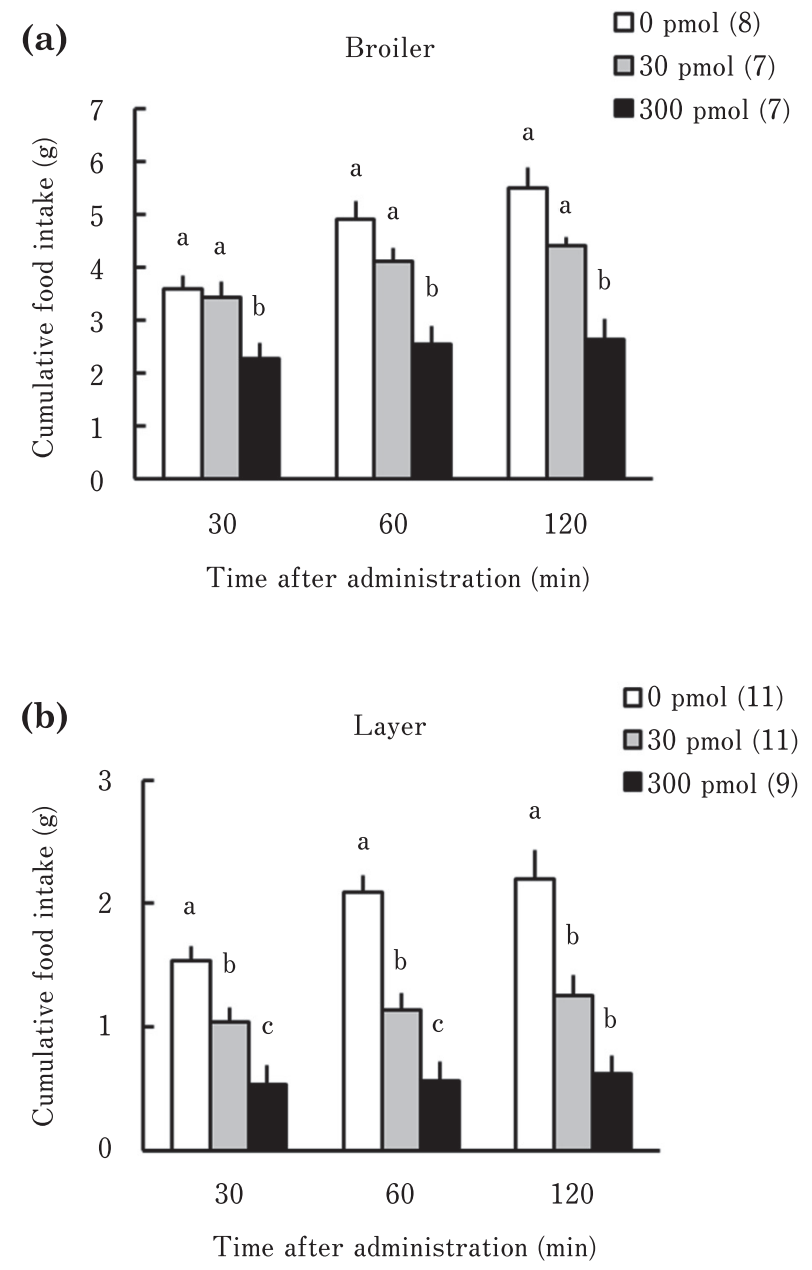

Fig. 4. Effects of central administration of insulin-like growth factor-1 (IGF-1) on food intake in broiler (a) and layer (b) chicks. The number of chicks used is shown in parentheses. Groups with different letters are significantly different $(p<0.05)$.

Metabolism, 8: 459-467. 2008.

Braun EJ and Sweazea KL. Glucose regulation in birds. Comparative Biochemistry and Physiology Part B: Biochemistry and Molecular Biology, 151: 1-9. 2008.

Bungo T, Shiraishi J and Kawakami S. Hypothalamic melanocortin system on feeding regulation in birds: a review. Journal of Poultry Science, 48: 1-13. 2011.

Burnside J and Cogburn LA. Developmental expression of hepatic growth hormone receptor and insulin-like growth factor-I mRNA in the chicken. Molecular and Cellular Endocrinology, 89: 91-96. 1992.

Davis JL, Masuoka DT, Gerbrandt LK and Cherkin A. Autoradiographic distribution of L-proline in chicks after intracerebral injection. Physiology \& Behavior, 22: 693-695. 1979.

Fujita S, Honda K, Hiramoto D, Gyu M, Okuda M, Nakayama S, Yamaguchi M, Saneyasu T and Kamisoyama H. Central and peripheral administrations of insulin-like growth factor-1 suppress food intake in chicks. Physiology \& Behavior, 179: 308312. 2017. 
Haissaguerre M, Saucisse N and Cota D. Influence of mTOR in energy and metabolic homeostasis. Molecular and Cellular Endocrinology, 397: 67-77. 2014.

Honda K, Saneyasu T, Hasegawa S and Kamisoyama H. A comparative study of the central effects of melanocortin peptides on food intake in broiler and layer chicks. Peptides, 37: 13-17. 2012.

Honda K, Saneyasu T and Kamisoyama H. Gut hormones and regulation of food intake in birds. Journal of Poultry Science, 54: 103-110. 2017.

Honda K, Saneyasu T, Okuda M, Uemura T and Kamisoyama H. Glucagon and neuromedin $\mathrm{U}$ suppress food intake in broiler chicks. Journal of Poultry Science, 52: 268-278. 2015.

Jia J, Ahmed I, Liu L, Liu Y, Xu Z, Duan X, Li Q, Dou T, Gu D, Rong H, Wang K, Li Z, Talpur MZ, Huang Y, Wang S, Yan S, Tong H, Zhao S, Zhao G, Te Pas MFW, Su Z and Ge C. Selection for growth rate and body size have altered the expression profiles of somatotropic axis genes in chickens. PLoS One, 13: e0195378. 2018.

Julian RJ. Production and growth related disorders and other metabolic diseases of poultry-a review. Veterinary Journal, 169: 350-369. 2005.

Kim MS, Pak YK, Jang PG, Namkoong C, Choi YS, Won JC, Kim KS, Kim SW, Kim HS, Park JY, Kim YB and Lee KU. Role of hypothalamic Foxo1 in the regulation of food intake and energy homeostasis. Nature Neuroscience, 9: 901-906. 2006.

Kita K, Hangsanet K, Shibata T, Conlon MA, Sasaki T, Saito N and Okumura J. Refeeding increases hepatic insulin-like growth factor-I (IGF-I) gene expression and plasma IGF-I concentration in fasted chicks. British Poultry Science, 39: 679-682. 1998.

Kita K, Tomas FM, Owens PC, Knowles SE, Forbes BE, Upton Z, Hughes R and Ballard FJ. Influence of nutrition on hepatic IGF-I mRNA levels and plasma concentrations of IGF-I and IGF-II in meat-type chickens. Journal of Endocrinology, 149: 181-190. 1996.

Kuenzel WJ. Central neuroanatomical systems involved in the regulation of food intake in birds and mammals. Journal of Nutrition, 124: 1355S-1370S. 1994.

Leili S, Buonomo FC and Scanes CG. The effects of dietary restriction on insulin-like growth factor (IGF)-I and II, and IGFbinding proteins in chickens. Proceedings of the Society for Experimental Biology and Medicine, 216: 104-111. 1997.

Liu L, Song Z, Jiao H and Lin H. Glucocorticoids increase NPY gene expression via hypothalamic AMPK signaling in broiler chicks. Endocrinology, 155: 2190-2198. 2014.

Lu H, Martinez-Nieves B, Lapanowski K and Dunbar J. Intracerebroventricular insulin-like growth factor-1 decreases feeding in diabetic rats. Endocrine, 14: 349-352. 2001.

Nakashima K, Ishida A, Shimamoto S. Ijiri D and Ohtsuka A. Effects of insulin-like growth factor-I on the expression of atrogin-1/MAFbx in chick myotube cultures. Journal of Poultry Science, 54: 247-252. 2017.

Radhakrishnan Y, Busby WH Jr, Shen X, Maile LA and Clemmons DR. Insulin-like growth factor-I-stimulated insulin receptor substrate-1 negatively regulates Src homology 2 domaincontaining protein-tyrosine phosphatase substrate-1 function in vascular smooth muscle cells. Journal of Biological Chemistry, 285: 15682-15695. 2010.

Richards MP and Proszkowiec-Weglarz M. Mechanisms regulating feed intake, energy expenditure, and body weight in poultry. Poultry Science, 86: 1478-1490. 2007.
Sam AH, Troke RC, Tan TM and Bewick GA. The role of the gut/ brain axis in modulating food intake. Neuropharmacology, 63: 46-56. 2012.

Saneyasu T, Fujita S, Kitashiro A, Fukuzo S, Honda K and Kamisoyama H. Hypothalamic Akt-mediated signaling regulates food intake in chicks. Neuroscience Letters, 670: 48-52. 2018.

Saneyasu T, Honda K, Kamisoyama H, Ikura A, Nakayama Y and Hasegawa S. Neuropeptide Y effect on food intake in broiler and layer chicks. Comparative Biochemistry and Physiology Part A: Molecular \& Integrative Physiology, 159: 422-426. 2011.

Saneyasu T, Inui M, Kimura S, Yoshimoto Y, Tsuchii N, Shindo H, Honda $\mathrm{K}$ and Kamisoyama $\mathrm{H}$. The IGF-1/Akt/S6 signaling pathway is age-dependently downregulated in the chicken breast muscle. Journal of Poultry Science, 53: 213-219. 2016.

Saneyasu T, Shiragaki M, Kurachi K, Kamisoyama H and Honda K. Effects of short-term refeeding on the expression of genes involved in lipid metabolism in chicks (Gallus gallus). Comparative Biochemistry and Physiology Part B: Biochemistry and Molecular Biology, 166: 1-6. 2013.

Saneyasu T, Tsuchii N, Nakano Y, Kitashiro A, Tsuchihashi T, Shindo H, Honda K and Kamisoyama H. Effects of short-term fasting on the Akt-mediated pathway involved in protein metabolism in chicken skeletal muscle. Domestic Animal Endocrinology, 61: 54-61. 2017.

Sasaki T and Kitamura T. Roles of FoxO1 and Sirt1 in the central regulation of food intake. Endocrine Journal, 57: 939-946. 2010.

Shiraishi J, Yanagita K, Fukumori R, Sugino T, Fujita M, Kawakami S, McMurtry JP and Bungo T. Comparisons of insulin related parameters in commercial-type chicks: Evidence for insulin resistance in broiler chicks. Physiology \& Behavior, 103: 233239. 2011.

Song Z, Liu L, Yue Y, Jiao H, Lin H, Sheikhahmadi A, Everaert N, Decuypere E and Buyse J. Fasting alters protein expression of AMP-activated protein kinase in the hypothalamus of broiler chicks (Gallus gallus domesticus). General and Comparative Endocrinology, 178: 546-555. 2012.

Tachibana T, Sato M, Oikawa D and Furuse M. Involvement of CRF on the anorexic effect of GLP-1 in layer chicks. Comparative Biochemistry and Physiology Part A: Molecular and Integrative Physiology, 143: 112-117. 2006.

Tachibana T, Sugahara K, Ohgushi A, Ando R, Kawakami S, Yoshimatsu $\mathrm{T}$ and Furuse M. Intracerebroventricular injection of agouti-related protein attenuates the anorexigenic effect of alpha-melanocyte stimulating hormone in neonatal chicks. Neuroscience Letters, 305: 131-134. 2001.

Tachibana T, Takagi T, Tomonaga S, Ohgushi A, Ando R, Denbow DM and Furuse M. Central administration of cocaine- and amphetamine-regulated transcript inhibits food intake in chicks. Neuroscience Letters, 337: 131-134. 2003.

Tesseraud S, Métayer S, Duchêne S, Bigot K, Grizard J and Dupont J. Regulation of protein metabolism by insulin: value of different approaches and animal models. Domestic Animal Endocrinology, 33: 123-142. 2007.

Tomas FM, Pym RA, McMurtry JP and Francis GL. Insulin-like growth factor (IGF)-I but not IGF-II promotes lean growth and feed efficiency in broiler chickens. General and Comparative Endocrinology, 110: 262-275. 1998.

Willson NL, Forder REA, Tearle R, Williams JL, Hughes RJ, Nattrass GS and Hynd PI. Transcriptional analysis of liver from 
chickens with fast (meat bird), moderate (F1 layer x meat bird cross) and low (layer bird) growth potential. BMC Genomics, 19: 309. 2018.

Xiao Y, Wu C, Li K, Gui G, Zhang G and Yang H. Association of growth rate with hormone levels and myogenic gene expression profile in broilers. Journal of Animal Science and Biotechnology, 8: 43. 2017.

Yu M, Wang H, Xu Y, Yu D, Li D, Liu X and Du W. Insulin-like growth factor-1 (IGF-1) promotes myoblast proliferation and skeletal muscle growth of embryonic chickens via the PI3K/ Akt signaling pathway. Cell Biology International, 39: 910922. 2015.
Yuan L, Ni Y, Barth S, Wang Y, Grossmann R and Zhao R. Layer and broiler chicks exhibit similar hypothalamic expression of orexigenic neuropeptides but distinct expression of genes related to energy homeostasis and obesity. Brain Research, 1273: 18-28. 2009.

Zhao R, Muehlbauer E, Decuypere E and Grossmann R. Effect of genotype-nutrition interaction on growth and somatotropic gene expression in the chicken. General and Comparative Endocrinology, 136: 2-11. 2004.

Zeltser LM, Seeley RJ and Tschöp MH. Synaptic plasticity in neuronal circuits regulating energy balance. Nature Neuroscience, 15: 1336-1342. 2012. 